\title{
Review Article \\ Nanotechnology in Cancer Drug Delivery and Selective Targeting
}

\author{
Kumar Bishwajit Sutradhar and Md. Lutful Amin \\ Department of Pharmacy, Stamford University Bangladesh, 51 Siddeswari Road, Dhaka 1217, Bangladesh \\ Correspondence should be addressed to Kumar Bishwajit Sutradhar; kumarbishwajit.pharm@gmail.com
}

Received 24 September 2013; Accepted 28 October 2013; Published 16 January 2014

Academic Editors: C. Alexiou, H. Duan, and I. H. El-Sayed

Copyright (C) 2014 K. B. Sutradhar and Md. L. Amin. This is an open access article distributed under the Creative Commons Attribution License, which permits unrestricted use, distribution, and reproduction in any medium, provided the original work is properly cited.

\begin{abstract}
Nanoparticles are rapidly being developed and trialed to overcome several limitations of traditional drug delivery systems and are coming up as a distinct therapeutics for cancer treatment. Conventional chemotherapeutics possess some serious side effects including damage of the immune system and other organs with rapidly proliferating cells due to nonspecific targeting, lack of solubility, and inability to enter the core of the tumors resulting in impaired treatment with reduced dose and with low survival rate. Nanotechnology has provided the opportunity to get direct access of the cancerous cells selectively with increased drug localization and cellular uptake. Nanoparticles can be programmed for recognizing the cancerous cells and giving selective and accurate drug delivery avoiding interaction with the healthy cells. This review focuses on cell recognizing ability of nanoparticles by various strategies having unique identifying properties that distinguish them from previous anticancer therapies. It also discusses specific drug delivery by nanoparticles inside the cells illustrating many successful researches and how nanoparticles remove the side effects of conventional therapies with tailored cancer treatment.
\end{abstract}

\section{Introduction}

Cancer is one of the most serious fatal diseases in today's world that kills millions of people every year. It is one of the major health concerns of the 21st century which does not have any boundary and can affect any organ of people from any place [1]. Cancer, the uncontrolled proliferation of cells where apoptosis is greatly disappeared, requires very complex process of treatment. Because of complexity in genetic and phenotypic levels, it shows clinical diversity and therapeutic resistance. A variety of approaches are being practiced for the treatment of cancer each of which has some significant limitations and side effects [2]. Cancer treatment includes surgical removal, chemotherapy, radiation, and hormone therapy. Chemotherapy, a very common treatment, delivers anticancer drugs systemically to patients forquenching the uncontrolled proliferation of cancerous cells [3]. Unfortunately, due to nonspecific targeting by anticancer agents, many side effects occur and poor drug delivery of those agents cannot bring out the desired outcome in most of the cases. Cancer drug development involves a very complex procedure which is associated with advanced polymer chemistry and electronic engineering. The main challenge of cancer therapeutics is to differentiate the cancerous cells and the normal body cells. That is why the main objective becomes engineering the drug in such a way as it can identify the cancer cells to diminish their growth and proliferation. Conventional chemotherapy fails to target the cancerous cells selectively without interacting with the normal body cells. Thus they cause serious side effects including organ damage resulting in impaired treatment with lower dose and ultimately low survival rates [4].

Nanotechnology is the science that usually deals with the size range from a few nanometers $(\mathrm{nm})$ to several hundred $\mathrm{nm}$, depending on their intended use [5]. It has been the area of interest over the last decade for developing precise drug delivery systems as it offers numerous benefits to overcome the limitations of conventional formulations [6,7]. It is very promising both in cancer diagnosis and treatment since it can enter the tissues at molecular level. Cancer nanotechnology is being enthusiastically evaluated and implemented in cancer treatment indicating a major advance in detection, diagnosis, 
and treatment of the disease. Various researches are being carried out in order to discover more accurate nanotechnology based cancer treatment minimizing the side effects of the conventional ones [5]. Nanoparticles are now being designed to assist therapeutic agents to pass through biologic barriers, to mediate molecular interactions, and to identify molecular changes. They have larger surface area with modifiable opti$\mathrm{cal}$, electronic, magnetic, and biologic properties compared to macroparticles. Current nanotechnology based drug delivery systems for cancer treatment, which are already marketed and under research and evaluation, include liposomes, polymeric micelles, dendrimers, nanospheres, nanocapsules, and nanotubes $[8,9]$. Nanotechnology based formulations that have already been marketed are DOXIL (liposomal doxorubicin) and Abraxane (albumin bound paclitaxel) [10].

\section{Limitations of Conventional Chemotherapy}

Conventional chemotherapeutic agents work by destroying rapidly dividing cells, which is the main property of neoplastic cells. This is why chemotherapy also damages normal healthy cells that divide rapidly such as cells in the bone marrow, macrophages, digestive tract, and hair follicles [2]. The main drawback of conventional chemotherapy is that it cannot give selective action only to the cancerous cells. This results in common side effects of most chemotherapeutic agents which include myelosuppression (decreased production of white blood cells causing immunosuppression), mucositis (inflammation of the lining of the digestive tract), alopecia (hair loss), organ dysfunction, and even anemia or thrombocytopenia. These side effects sometimes impose dose reduction, treatment delay, or discontinuance of the given therapy [11, 12]. In case of solid tumors cell division may be effectively ceased near the center, making chemotherapeutic agents insensitive to chemotherapy. Furthermore, chemotherapeutic agents often cannot penetrate and reach the core of solid tumors, failing to kill the cancerous cells [13].

Traditional chemotherapeutic agents often get washed out from the circulation being engulfed by macrophages. Thus they remain in the circulation for a very short time and cannot interact with the cancerous cells making the chemotherapy completely ineffective. The poor solubility of the drugs is also a major problem in conventional chemotherapy making them unable to penetrate the biological membranes [4]. Another problem is associated with Pglycoprotein, a multidrug resistance protein that is overexpressed on the surface of the cancerous cells, which prevents drug accumulation inside the tumor, acting as the efflux pump, and often mediates the development of resistance to anticancer drugs. Thus the administered drugs remain unsuccessful or cannot bring the desired output [14-17].

\section{Nanotechnology in Cancer Targeting}

Nanotechnology has made a great revolution in selective cancer targeting. Nanoparticles can be designed through various modifications such as changing their size, shape, chemical and physical properties, and so forth, to program them for targeting the desired cells. They can target the neoplastic cells either through active or passive targeting.

3.1. Active Targeting. In case of active targeting, nanoparticles containing the chemotherapeutic agents are designed in such a way as they directly interact with the defected cells. Active targeting is based on molecular recognition. Hence, the surface of the nanoparticles is modified to target the cancerous cells. Usually, targeting agents are attached with the surface of nanoparticles for molecular recognition. Designed nanoparticles target the cancerous cells either by ligandreceptor interaction or antibody-antigen recognition [18-20]. Nanotechnology based targeted delivery system has three main components: (i) an apoptosis-inducing agent (anticancer drug), (ii) a targeting moiety-penetration enhancer, and (iii) a carrier. A variety of substances are used to construct a nanoparticle. Commonly used materials include ceramic, polymers, lipids, and metals [21]. Natural and synthetic polymers and lipids are typically used as drug delivery vectors [22-24]. Particles containing chemotherapeutic agents are engulfed by phagocytes and rapidly cleared by the reticuloendothelial system (RES). A variety of strategies were developed to sustain the nanoparticles in blood stream one of which is the alteration of the polymeric composition of the carrier. Nanoparticles are coated with hydrophilic polymers to avoid wash out and remain in the bloodstream for a longer period of time that can sufficiently target cancerous cells. Hydrophilic polymer coating on the nanoparticle surface repels plasma proteins and escapes from being opsonized and cleared. This is described as a "cloud" effect [25-28]. Commonly used hydrophilic polymers include polyethylene glycol (PEG), poloxamines, poloxamers, polysaccharides, and so forth $[29,30]$. Cancerous cells have some unique properties that differentiate them from the healthy cells at molecular level. Some receptors are over expressed on the surface of them that make the distinguishing feature. Attachment of the complementary ligands on the surface of nanoparticles makes them able to target only the cancerous cells. Once the nanoparticles bind with the receptors, they rapidly undergo receptor-mediated endocytosis or phagocytosis by cells, resulting in cell internalization of the encapsulated drug. Numerous works are being done to investigate these ligandreceptor interactions and utilize them for clinical use [5].

\subsubsection{Specific Receptor Targeting}

Folate Receptor. Folate receptors are overexpressed in many neoplastic cells providing a target for certain anticancer therapies. Utilizing the concept, researchers are designing the surface of nanoparticles with folic acid [31-33]. Russell-Jones et al. examined the potential of using folic acid as a targeting agent for the delivery of pHPMA conjugated daunomycin in four murine tumor models. Folic acid targeted daunomycinHPMA conjugates were found to increase both the number of survivors and the survival time of tumor-bearing mice. The data indicate that folic acid may be highly effective in enhancing the efficacy of other polymer-bound cytotoxins [34]. 
Another study was done by a team led by KukowskaLatalloto et al. which tests the folate-linked methotrexate dendrimers in immunodeficient athymic nude female mice. The mice were injected with the nanoconjugates twice a week via a lateral tail vein. The results showed that conjugated methotrexate in dendrimers significantly lowered toxicity and resulted in a 10 -fold higher efficacy compared to free methotrexate at an equal cumulative dose. As a result, mice survived longer [33]. The efficacy of nanosized folate receptor-targeted doxorubicin aggregates was tested for cancer treatment. Doxorubicin-polyethylene glycol-folate conjugate micelles were prepared that were $200 \mathrm{~nm}$ in average diameter. The polymeric micelles exhibited enhanced and selective targeting to folate receptor positive cancer cells in vitro. The in vivo animal experiments showed that the nanoaggregates caused significant tumor suppression [35, 36].

Some other preparations include nanoparticles to which folate was conjugated covalently using surface carboxyl groups as well as conjugation of folate to hydrazine modified poly-lactic acid nanoparticles. Isobutyl-cyanoacrylate (IBCA) nanocapsules were prepared and coated with folate that showed a significantly increased efficacy of nanocapsules targeted to the tumor [8]. The experiments showed folate receptors can be targeted very effectively for selective drug delivery by nanoparticles conjugated to folic acid.

Transferrin Receptor. Nanoparticles are widely being investigated to target the transferrin receptors for binding and cell entry, as these are overexpressed by certain tumor cells to increase their iron uptake. Transferrin (Tf) can be conjugated to a variety of materials for cancer targeting which include Tf-chemotherapeutic agent, Tf-toxic protein, Tf-RNases, Tfantibody, and Tf-peptide [37, 38]. Kawamoto et al. found that Tf-lytic hybrid peptide can selectively target cancerous cells. They administered Tf-lytic peptide in an athymic mice model with MDA-MB-231 cells. The Tf-lytic hybrid peptide showed effective cytotoxic activity where normal cells were less sensitive to this molecule. It was additionally revealed that this preparation can disintegrate the cell membrane of T47D cancer cells just in 10 min, killing them effectively and inducing approximately $80 \%$ apoptotic cell death but not in normal cells. Thus the intravenous administration of Tf-lytic peptide in the athymic mice model significantly inhibited tumor progression [37]. Bellocq et al. found that, at low transferrin modification, the nanoparticles remain stable in physiologic salt concentrations and transfect leukemia cells with increased efficiency. The transferrin-modified nanoparticles are effective for systemic delivery of nucleic acid therapeutics for metastatic cancer $[39,40]$.

Luteinizing Hormone-Releasing Hormone Receptor. Luteinizing hormone-releasing hormone (LHRH) is being used in many ongoing researches as a targeting moiety (ligand) to LHRH receptors that are over-expressed in the plasma membrane of various types of cancer cells like breast cancer, ovarian cancer, and prostate cancer [41, 42]. Farokhzad, Langer, and colleagues developed a new technique to deliver the drugs in cancer cell's internal fluid. They laced tailor-made tiny sponge-like nanoparticles with the drug, docetaxel. The particles were particularly designed to dissolve the drug in a cell's internal fluids, controlling the release rate. For selective targeting, the nanoparticles were "decorated" on the outside with targeting molecules called aptamers, tiny chunks of genetic material. The aptamers specifically recognize the surface molecules on cancer cells. In addition, the nanoparticles also contained polyethylene glycol molecules to keep them away from being rapidly destroyed by macrophages [43].

A team, led by Prasad, developed a method of targeting LHRH receptor with ferric oxide nanoparticles which was prepared by a reverse micelle colloidal reaction. The hydrophilic groups were sequestered in the micelle core and the hydrophobic groups remained solvent exposed on the surface of the micelle in a reverse micelle system which was formed by a surfactant, continuous oil phase, and water. A tracking agent, two-photon dye ASPI-SH, was attached to the surface of the iron oxide. Silica was added to form the structure of the silica shell before additional silica shell grown by tetraethylorthosilicate hydrolysis. The targeting agent LHRH was coupled to the silica shell through carbon spacers so as to prevent stearic hindrance during the interaction of the targeting agent with its complementary molecule on cells. After the administration of the nanoparticles, the patients were exposed to a DC magnetic field. The selective interaction, internalization, and so forth were investigated by using LHRH receptor expressing cells on oral epithelial carcinoma cells. Data clearly showed that the nanoparticles selectively interacted with the specific cell types [8].

Asialoglycoprotein. Asialoglycoprotein (ASGP), another receptor which is overexpressed in hepatoma, is utilized in cancer targeting by nanoparticles for anticancer drug delivery. Sung and coworkers developed a new strategy by which biodegradable nanoparticles with a mean size of $140 \mathrm{~nm}$ can be prepared to target the hepatoma cells. They prepared them from poly $(-\gamma$-glutamic acid)-poly (lactide) block copolymers loaded with paclitaxel using emulsion solvent evaporation technique. The nanoparticles were conjugated with galactosamine (GAL) through an amide linkage to enhance hepatoma HepG2 cell uptake by targeting ASGP receptors. Immunofluorescence analysis utilizing a rhodamine-123 probe, encapsulated in the hydrophobic core of the gal-nanoparticles, revealed the high degree of selectivity of the nanoparticles to hepatic tumors with enhanced cellular uptake through receptormediated endocytosis resulting in subsequent release of the encapsulated paclitaxel inside the cytoplasm. Those nanoparticles inhibited the growth of the cells with a consequent decrease in systemic toxicity compared to free paclitaxel.

A dual-particle tumor targeting system was developed for selectively inhibiting angiogenesis in hepatoma. Nanoparticle, encapsulating ganciclovir conjugated with galactosamine, was the first component and an enhanced permeability and retention (EPR) mediated targeting nanoparticle containing an HSV thymidine kinase (TK) gene was the second component of the dual-particle tumor targeting system. It was stated that thymidine kinase would digest ganciclovir to produce 
cytotoxic effects after cancer cells internalization of the first and second nanoparticles together. Thus it kills the targeted cancer cells [8].

3.1.2. Antibody Mediated Targeting. Many tumor cells show unusual antigens due to their genetic defects, that are either inappropriate for the cell type, environment, or temporal placement in the organisms' development. The immune responses educed by tumor antigens are not so strong because they are recognized as own cells. Highly specific monoclonal antibodies (mAbs) are used to strengthen the immune response and to intensify the immune system's antitumor capacity. These antibodies target proteins that are abnormally expressed in neoplastic cells and are essential for their growth. Nanoparticles conjugated with an antibody against a specific tumor antigen are developed for selective drug delivery [7]. Most of the mAbs are produced by the clones of a single hybridoma cell. The hybridoma cell results from the fusion of a myeloma that produces antibody and an antigenically stimulated normal plasma cell to bind specifically to tumor cell antigens. After binding with tumor antigens, mAbs can destroy cancer cells through a variety of approaches which include directly inducing apoptosis, blocking growth factor receptors, and anti-idiotype formation. They can indirectly eradicate cancer cells by activating complement mediated cellular cytotoxicity and antibody dependent cell mediated cytotoxicity [8]. Antibody engineering has recently flourished with the outcome of antibody production that contains animal and human origins such as chimeric mAbs, humanized mAbs (those with a greater human contribution), and antibody fragments. Antibodies can be used in their original form or as fragments for cancer targeting. However, the presence of two binding sites (within a single antibody) gives higher binding opportunity and makes it advantageous to use the intact mAbs. Moreover, a signaling cascade is initiated to kill the cancer cells when macrophages bind to the Fc segment of the antibody. The Fc portion of an intact mAb can also bind to the Fc receptors on normal cells resulting in increased ability to evoke an immune response and liver and spleen uptake of the nanocarrier. Stability in long-term storage is their additional advantage. On the other hand, antibody fragments including antigen-binding fragments (Fab), dimers of antigen-binding fragments $\left(\mathrm{F}\left(\mathrm{ab}^{\prime}\right) 2\right)$, single-chain fragment variables $(\mathrm{scFv})$, and other engineered fragments are considered safer with reduced nonspecific binding [5, $44,45]$. Phage display libraries may be used to rapidly select antibodies or their fragments that bind to and internalize within cancer cells. This method generates a combination of potentially useful antibodies that bind to different epitopes (a part of a receptor that is recognized by antibodies) of the same target cells. Thus several epitopes of a single receptor will be recognized by multiple antibodies proving more accurate and selective action [46-48]. The efficacy of antibodies can be increased by conjugating a therapeutic agent directly to it. mAbs can act as the highly specific probes when they are attached to nanoparticles to aid in targeted delivery of various antitumor cytotoxic agents [5]. Binding affinity and selectivity to cell surface targets by engineering proteins can also be increased through the detection of a specific conformation of a target receptor. A fusion protein consisting of an $\mathrm{scFv}$ antibody fragment, to target and deliver small interfering RNA (siRNA) to lymphocytes, showed a 10,000fold increased affinity for the target receptor, integrin LFA-1 in a recent study done by Peer et al. [49].

Kuroda and fellows developed a method for the preparation of hollow protein nanoparticles containing ganciclovir which encapsulates a hepatic cancer therapeutic gene, thymidine kinase (HSV1tk), derived from simple herpes virus. The nanoparticles were modified by displaying a hepatitis $\mathrm{B}$ virus surface-antigen to own hepatocyte recognition ability and particle formation ability. A human hepatoma bearing animal model demonstrated that when a hepatic cancertreating gene was encapsulated into hepatitis B virus surfaceantigen (HBsAg) particles, the gene was specifically delivered into a human liver-derived tissue part after administering the particles through intravenous injection. The therapeutic effect of the HBsAg-HSV1tk hollow protein nanoparticles specific to hepatic cancer was also confirmed. They also developed a method of encapsulating cytotoxic drug, containing a cancer treating gene, within nanoparticles modified to display an antibody used for specific targeting of human squamous carcinoma cells. The nanoparticles were modified to express an antibody that recognizes the epidermal growth factor receptor, expressed by the cancer cells. Animal studies confirmed that the transfer and expression of the gene was very specific to the human squamous carcinoma and highly effective in treatment [8]. Wartlick et al. developed biodegradable nanoparticles based on gelatin and human serum albumin in which the surface of the nanoparticles was modified by covalent attachment of the biotin-binding protein NeutrAvidin, enabling the binding of biotinylated drug targeting ligands by avidin-biotin complex formation. HER2 receptor, a member of the epidermal growth factor receptor family, is overexpressed in certain types of cancer (breast cancer). HER2 receptor specific antibody trastuzumab (herceptin) was conjugated to the surface of these nanoparticles for targeting HER2-overexpressing cells. Confocal laser scanning microscopy showed an effective internalization of these nanoparticles by HER2-overexpressing cells through receptor-mediated endocytosis [50].

Nanoparticles can be designed to enhance Fas ligand expression, a type-II transmembrane protein which induces apoptosis when bound with its receptor, on the surface of Fas receptor-expressing leukemia cells. Fas ligand-receptor interactions play a significant role in the regulation of the immune system and the progression of cancer [51, 52]. Fas agonist $\mathrm{CH}-11$, a monoclonal antibody to the Fas receptor, is conventionally used to target the cancer cells. The mAb rituximab (Rituxan) was approved in 1997 for the treatment of patients with non-Hodgkin's lymphoma.

3.1.3. Antiangiogenesis. Angiogenesis is described as the growth of new blood vessels from preexisting vessels. Tumors cannot grow more than $2 \mathrm{~mm}$ in diameter without angiogenesis [53-55]. Cancerous cells produce abnormal amounts of angiogenic growth factors resulting in an excessive angiogenesis overwhelming the effects of natural angiogenesis inhibitors giving rise to leaky and tortuous 
vessels that are in a constant state of inflammation [5458]. Studies on breast cancer showed that the degree of metastasis, tumor recurrence, and shorter survival rates are correlated with angiogenesis $[56,59]$. Antiangiogenesis therapy is designed based on two mechanisms: drugs which prevent the formation of new blood vessels that supply to the tumor (e.g., TNP-470, endostatin, and angiostatin) or drugs that destroy the existing blood vessels (e.g., combretastatin) [60]. The objective of antiangiogenic therapy is to delay both primary and metastatic tumor growth by blocking the supply of essential nutrients and the removal of metabolites causing stunted tumor growth thereby avoiding tumor spread as well as enhancing the shrinkage of tumors [61]. Antiangiogenic drugs either act directly by targeting endothelial receptors or indirectly by targeting angiogenic cytokines [62-64]. Active targeting of the tumor vasculature by nanoparticles is achieved by targeting the VEGF receptors (VEGFRs), $\alpha_{v} \beta_{3}$ integrin receptors, and other angiogenic factors. Integrins, which mediate the attachment between a cell and its surroundings, are the main component in angiogenesis process and their increase in number enhances the survival, growth, and invasion of both tumor and endothelial cells [64, 65]. $\alpha_{v} \beta_{3}$ integrin antibody has been widely used as a targeting moiety on nanovectors for anti-angiogenesis therapy due to its pleitropic upregulation in many tumor settings. Some of them have passed several clinical trials [66-69]. Tumor angiogenesis was successfully detected in rabbit and mouse models by perfluorocarbon nanoparticles conjugated to various contrasting agents (Gadolinium, Gd, or fluorine isotope $\left.19,{ }^{19} \mathrm{~F}\right)$ and linked to an $\alpha_{v} \beta_{3}$ integrin antibody $[66,68]$. The use of peptides as the targeting agents resulted in increased intracellular drug delivery in different murine tumor models $[70,71]$. An approach to target integrin overexpression involves using a synthetic peptide containing the recognition site for integrins, namely an arginine-glycine-aspartic acid (RGD) sequence [67]. The first angiogenesis inhibitor for colorectal cancer therapy, bevacizumab (Avastin), an antiVEGF mAb that inhibits the growth factor of new blood vessels, was approved in 2004 [5, 72]. Prokop and his team developed a method of preparing biocompatible nanoparticle that can be used as drug delivery vehicles. They were designed to retain and deliver Antiangiogenic compounds over an extended period of time for targeting tumor vasculature. Nanoparticles were formulated comprising a hydrophilic core of sodium alginate, cellulose sulfate, and Antiangiogenic factors such as thrombospondin (TSP)-1 or TSP-517 which was crosslinked with dextran polyaldehyde with calcium chloride or conjugated to heparin sulfate with sodium chloride. In addition, luciferase (bioluminescent agent) or polymeric gadolinium (contrast agent) was placed within the polyanionic core. The hydrophilic shell surrounding the core additionally contained spermine hydrochloride, poly(methylene-co-guanidine) hydrochloride, and pluronic F-68, calcium chloride, and a targeting ligand conjugated to an activated polyethylene glycol or crosslinked to dextran polyaldehyde. Targeted nanoparticles were evaluated by monitoring luciferase in a murine model [8]. Figure 1 illustrates the process of active targeting.
3.2. Passive Targeting. Nanoparticles can also target cancer through passive targeting. As apoptosis is stopped in cancerous cells, they continue sucking nutritious agents abnormally through the blood vessels forming wide and leaky blood vessels around the cells induced by angiogenesis. Leaky blood vessels are formed due to basement membrane abnormalities and decreased numbers of pericytes lining rapidly proliferating endothelial cells [73]. Hence, the permeability of molecules to pass through the vessel wall into the interstitium surrounding tumor cells is increased. The size of the pores in leaky endothelial cells ranges from 100 to $780 \mathrm{~nm}$ [74-76]. Thus nanoparticles below that size can easily pass through the pores $[77,78]$. As a result, it facilitates to efflux the nanoparticles to cluster around the neoplastic cells. Nanoparticles can be targeted to specific area of capillary endothelium, to concentrate the drug within a particular organ and perforate the tumor cells by passive diffusion or convection. Lack of lymphatic drainage eases the diffusion process. The tumor interstitium is composed of a collagen network and a gel like fluid. The fluid has high interstitial pressures which resist the inward flux of molecules. Tumors also lack well-defined lymphatic networks having leaky vasculature. Therefore, drugs that enter the interstitial area may have extended retention times in the tumor interstitium. This feature is called the enhanced permeability and retention (EPR) effect and facilitates tumor interstitial drug accumulation (Figure 1) $[79,80]$. Nanoparticles can easily accumulate selectively by enhanced permeability and retention effect and then diffuse into the cells [81].

\section{Cellular Uptake, pH Dependent Drug Delivery, and Prevention from Lysosomal Degradation}

Active or passive targeted nanoparticles face a major difficulty in releasing drugs in the neoplastic cells since lysosomal enzymes rapidly destroy both the nanoparticles and drugs inside the cells. After internalization, the colloidal carriers usually reach the lysosomal compartment, in which hydrolytic enzymes degrade both the carrier and its content. Therefore, the intracellular distribution of the carrier is modified when the encapsulated drug is a nucleic acid. Because $\mathrm{pH}$ around of tumors cells is more acidic, carriers that change solubility at lower $\mathrm{pH}$ can be used to target and release drugs. The extracellular environment of solid tumors is acidic and there is an altered $\mathrm{pH}$ gradient across their cell compartments. Nanoparticles sensitive to the $\mathrm{pH}$ gradients are promising for cancer drug delivery. A $\mathrm{pH}$ responsive nanoparticle consists of a shell and a core and it responds to the $\mathrm{pH}$ gradient and changes its solubility pattern. The core-shell polymer nanoparticles are designed with their lower critical solution temperature (LCST) being dependent on the ambient $\mathrm{pH}$ 7.4. At low $\mathrm{pH}$, in and around of tumor cells the resulting change in LCST causes the coreshell nanoparticles to deform and precipitate in an acidic environment, triggering the release the chemotherapeutics. A targeting molecule is additionally conjugated to the shell of the nanoparticles which can recognize tumor cells [82]. 


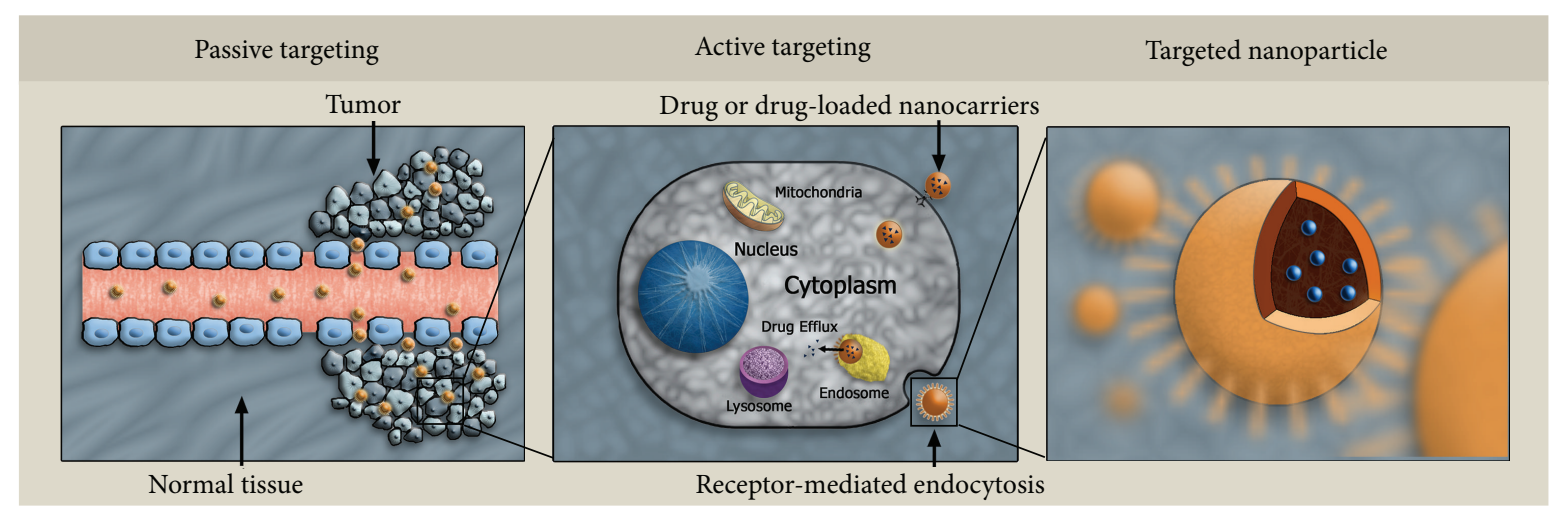

FIGURE 1: Active and passive targeting by nanoparticles.

Shefer and his team reported a new strategy for preparing a $\mathrm{pH}$ sensitive sustained release system for cancer treatment. The system utilizes solid hydrophobic nanospheres containing anticancer drugs that are encapsulated in a $\mathrm{pH}$ sensitive microsphere. It additionally included a bioadhesive material into the solid hydrophobic matrix of the nanospheres. The nanosphere hydrophobic matrix was formed by dispersing paclitaxel into the hot melt of candelilla wax. The microsphere of $\mathrm{pH}$ sensitive matrix was created by adding the drug/wax mixture into an aqueous solution containing a $\mathrm{pH}$ dependent anionic polymer which is stable at $\mathrm{pH} 7.4$ but solubilized at $\mathrm{pH} 6$ and lower. The prepared suspension was spray dried to produce a free flowing dry powder which consists of $10 \%$ paclitaxel. The nanospheres can release the drug over an extended period of time by dissolving/swelling the microsphere at a lower $\mathrm{pH}$ that is typically found in cancerous tissue [8]. Recently, researchers developed a system that either fuse with the plasma membrane or have a $\mathrm{pH}$-sensitive configuration that changes conformation in the lysosomes and allows the encapsulated material to escape into the cytoplasm [83]. Biodegradable nanoparticles were formulated from the copolymers of poly(d,1-lactide-co-glycolide) for their rapid endolysosomal escape. The system worked by selective reversal of the surface charge of nanoparticles (from anionic to cationic) in the acidic endolysosomal compartment causing the nanoparticles to interact with the endolysosomal membrane and escape into the cytosol. These nanoparticles can deliver wide ranged therapeutic agents, including macromolecules such as DNA at a slow rate, for sustained therapeutic effect. For using nanotechnology in cancer treatment, researchers developed thermoresponsive, pH-responsive, and biodegradable nanoparticles by grafting biodegradable poly (d,l-lactide) onto $\mathrm{N}$-isopropyl acrylamide and methacrylic acid. It may be sufficient for a carrier system to concentrate the drug (hydrophobic, that crosses the plasma membrane easily) in the target tissue [84].

\section{Hyperthermia}

Healthy cells are capable of surviving exposure to temperatures up to $46.5^{\circ} \mathrm{C}$. Irreversible cell damage occurs to the cancerous cells at temperatures from approximately $40^{\circ} \mathrm{C}$ to about $46^{\circ} \mathrm{C}$ due to the disorganized and compact vascular structure for which they are less stable. On the other hand, surrounding healthy cells are more readily able to spatter heat and maintain a normal temperature. This process stated above is called hyperthermia which is used for the purpose of damaging protein and structures within cancerous cells and in some cases, causing tumor cells to directly undergo apoptosis. Nanoparticles are utilized for a variety of purposes in hyperthermia-based treatments which include serving as the active thermotherapeutic agents, sensitizers and are also used for targeting purposes like antibody enhanced targeting to increase efficacy and to reduce hypothermia-associated side effects. Nanoparticles can locate and specifically target the deep-seated tissues and organs. Magnetic fluid hyperthermia is a well-practiced old method for cancer treatment. Small magnetic particles are used which respond to an externally applied magnetic field by heating up. In addition to specific targeting, nanoparticles add another benefit. Cells that have picked up some of the particles cannot get rid of them, and thus every daughter cell will have one half of the amount of particles present on the mother cell.

Handy et al. developed a method of manufacturing nanoparticles for targeted delivery of thermotherapy in cancer treatment. The prepared ferromagnetic nanoparticles were coated with biocompatible material poly(methacrylic acid-co-hydroxy-ethylmethacrylate) using free-radical polymerization. A stabilizing layer was formed around the magnetic particles by an ionic surfactant, sodium bis-2-ethylhexyl sulfosuccinate. For selective targeting, antibodies were covalently attached to the surface of coated magnetic particles. The thermotherapeutic magnetic composition containing singledomain magnetic particles attached to a target specific ligand was inductively heated using a magnetic field. High efficiency of the bioprobes was determined in animal model $[8,31]$.

\section{Combination of Drugs Having Different Physical Properties}

Several studies have recently shown that combination therapy is more effective than a single drug for many types of cancer. Drugs having different physical properties could not be combined into a single particle before. Furthermore, 
it has always been difficult to get the right amount of drug to the tumor. Langer and fellows developed a new method to develop nanoparticles in which they incorporated drugs with different physical properties, which had been impossible with previous drug delivering nanoparticles. Earlier generations of nanoparticles mean encapsulation in a polymer coating by which drugs with different charges or different affinity could not be carried together. The new technique, called "drugpolymer blending," allowed the researchers to hang the drug molecules like pendants from individual units of the polymer, before the units assemble into a polymer nanoparticle. They developed nanoparticles with hydrophobic docetaxel and hydrophilic cisplatin. After loading the drugs into the nanoparticle, the researchers added a tag that binds to a molecule called prostate-specific membrane antigen (PSMA), which is a type 2 integral membrane glycoprotein present on the surfaces of most prostate cancer cells. This tag allows the nanoparticles to bypass healthy tissues and reduce the side effects caused by most chemotherapy drugs. As a result, they go directly to their target region. The new technique facilitated them to precisely control the ratio of drugs loaded into the particle. They were also able to control release rate of the drugs after they entered the tumor cells [85].

\section{Overcoming Other Limitations of Conventional Chemotherapy}

Lack of solubility is one of the major limitations of most chemotherapeutic agents. Nanoparticles can effectively solve the solubility problem. Hydrophobic drugs can be encapsulated in micelles to increase their solubility [86, 87]. Dendrimers contain many binding sites with which both hydrophobic and hydrophilic molecules can bind. Liposomes also allow encapsulating hydrophobic drugs and transporting them to the desired area soon after administration [87]. Several approaches have been taken to overcome Pglycoprotein mediated drug resistance. P-glycoprotein locates drugs which are localized in the plasma membrane only. One strategy is to use the inhibiting agents such as verapamil or cyclosporine when concurrently administered with a cytotoxic drug can restrain P-glycoprotein. Thus both chemotherapeutic agent and inhibiting agent are incorporated into the nanoparticles to overcome the problem associated with P-glycoprotein $[25,88,89]$. A new strategy was developed for inhibition of the P-glycoprotein-mediated efflux of vincristine where vincristine-loaded lipid nanoparticles, conjugated to an anti-P-glycoprotein monoclonal antibody (MRK-16), showed greater cytotoxicity in resistant human myelogenous leukaemia cell lines than nontargeted particles [90]. Danson et al. developed SP1049C, a nonionic block copolymer composed of a hydrophobic core and hydrophilic tail that contains doxorubicin, which was able to circumvent P-glycoprotein mediated drug resistance in a mouse model of leukaemia and is now under clinical evaluation [91, 92]. In another study, folic acid, attached to polyethylenelglycol derivatized distearoyl-phosphatidylethanolamine, was used to target in vitro doxorubicin loaded liposomes to folate receptor overexpressing tumor cells. Folate receptormediated cell uptake of targeted liposomal doxorubicin into a multidrug resistant subline of M109-HiFR cells (M109RHiFR) was clearly unaffected by P-glycoprotein-mediated drug efflux, in sharp contrast to uptake of free doxorubicin [93].

\section{Targeting Agents}

Nanocarriers are used as targeting agents for cancer therapy comprising anticancer drugs, targeting moieties, and polymers. There are a variety of nanocarriers such as liposomes, dendrimers, micelles, carbon nanotubes, nanocapsules, nanospheres, and so forth. Therapeutic agents can be entrapped, covalently bound, encapsulated, or adsorbed to the nanoparticles $[5,8]$. Liposomes are composed of lipid bilayers where the core can be either hydrophilic or hydrophobic depending on the number of lipid bilayers $[102,103]$. Liposomes having a single lipid bilayer contain an aqueous core for encapsulating water soluble drugs, whereas other liposomes having more than a single bilayer entrap lipid soluble drugs $[103,104]$. They are readily cleared by the macrophages and are therefore coated with inert polymers for stabilization in the physiological conditions. Liposomes are commonly coated with polyethylene glycol (PEG) [21, $25,105-107]$. In vivo study shows that liposomes coated with hyaluronan (HA) improves circulation time and enhances targeting to HA receptor-expressing tumors $[108,109]$.Both active and passive targeting can be achieved with liposomal drug delivery. Liposomal nanoparticles can conjugate with either antibodies or ligands for selective drug delivery [110, 111]. They possess some advantages that they are biodegradation, nonantigenic and have a high transport rate [112]. They can also be designed for $\mathrm{pH}$ sensitive drug delivery or thermotherapy [113-115]. Dendrimers are branched three dimensional tree-like structures with a multifunctional core. They are synthesized from either synthetic or natural elements such as amino acids, sugars, and nucleotides [116]. Dendrimers can be prepared by controlled polymerization of the monomers maintaining desired shape and size. Multiple entities including both hydrophobic and hydrophilic molecules can be conjugated to dendrimers due to their exclusive branching point $[103,117-119]$. They can also be loaded with drugs using the cavities in their cores through hydrophobic interactions, hydrogen bonds, or chemical linkages. Dendrimers are capable of delivering genes, drugs, anticancer agents, and so forth [103]. Micelles are spherical structures where molecules with a hydrophobic end aggregate to form the central core and the hydrophilic ends of other molecules are in contact with the liquid environment surrounding the core. Micelles are effective carrier for the delivery of water insoluble drugs carried in the hydrophobic core $[103,118]$. Nanospheres are spherical in shape that is composed of a matrix system in which drug is evenly distributed by entrapment, attachment, or encapsulation. The surface of these nanoparticles can be modified by the addition of ligands or antibodies for targeting purposes. On the other hand, nanocapsules are like vesicles that have a central core where a drug is confined and a core is 
TABLE 1: Some formulations of nanoparticles with positive results in the recent investigations.

\begin{tabular}{|c|c|c|c|c|c|}
\hline $\begin{array}{l}\text { Type of } \\
\text { nanoparticle }\end{array}$ & Anticancer drug & Targeting agent & Name of the polymers used & Outcome & Reference \\
\hline $\begin{array}{l}\text { Polymeric } \\
\text { nanoparticle }\end{array}$ & Cystatin & $\begin{array}{l}\text { Cytokeratin specific } \\
\text { monoclonal antibody }\end{array}$ & $\begin{array}{l}\text { Poly(D, } \\
\text { L-lactidecoglycolide) and } \\
\text { polyethylene glycol }\end{array}$ & Prevent metastasis & {$[94]$} \\
\hline $\begin{array}{l}\text { Polymeric } \\
\text { nanoparticle }\end{array}$ & Paclitaxel & $\begin{array}{l}\text { Monoclonal antibodies } \\
\text { (antiHER2) }\end{array}$ & Poly(D, L-lactic acid) & Selective targeting & {$[95]$} \\
\hline $\begin{array}{l}\text { Polymeric } \\
\text { nanoparticle }\end{array}$ & Paclitaxel & Folic acid & $\begin{array}{l}\text { Polylactic acid and } \\
\text { polyethylene glycol }\end{array}$ & $\begin{array}{l}\text { Enhanced drug } \\
\text { accumulation in } \\
\text { tumor }\end{array}$ & {$[96]$} \\
\hline Dendrimer & - & Folic acid & Polyamidoamine & $\begin{array}{l}\text { Increased cellular } \\
\text { uptake }\end{array}$ & {$[97]$} \\
\hline Nanoshell & Docetaxel & Folic acid & Biodegradable polymer & $\begin{array}{l}\text { Sustainable, } \\
\text { controlled, and } \\
\text { targeted delivery }\end{array}$ & {$[98]$} \\
\hline Dendrimer & $\begin{array}{l}\text { Small } \\
\text { interfering RNA } \\
\text { (siRNA) }\end{array}$ & $\begin{array}{l}\text { Luteinizing } \\
\text { hormone-releasing } \\
\text { hormone (LHRH) peptide }\end{array}$ & $\begin{array}{l}\text { Poly(propyleneimine) and } \\
\text { polyethylene glycol }\end{array}$ & High specificity & [99] \\
\hline Nanoparticle & Paclitaxel & Folic acid & $\begin{array}{l}\text { Poly(D, } \\
\text { L-lactidecoglycolide) }\end{array}$ & $\begin{array}{l}\text { Inhibition of } \\
\text { P-glycoprotein }\end{array}$ & {$[100]$} \\
\hline Polymer micelle & Doxorubicin & Folic acid & $\begin{array}{l}\text { PEG-co-poly(lactic-co- } \\
\text { glycolic } \\
\text { acid) }\end{array}$ & $\begin{array}{l}\text { Increased cellular } \\
\text { uptake and } \\
\text { cytotoxicity }\end{array}$ & {$[101]$} \\
\hline Polymer micelle & Doxorubicin & Folic acid & $\begin{array}{l}\text { PEG-poly(aspartate } \\
\text { hydrazone doxorubicin) }\end{array}$ & $\begin{array}{l}\text { Increased endocytotic } \\
\text { cellular uptake }\end{array}$ & {$[101]$} \\
\hline
\end{tabular}

surrounded by a polymeric membrane. Targeting ligands or antibodies can be attached to the surface [25, 102]. Fullerenes (also called bucky balls) and nanotubes are a family of molecules composed of carbon in the form of a hollow sphere or ellipsoid tube. Atoms may be trapped inside fullerenes while antibodies or ligands are bound to the surface for targeting $[103,117]$. Carbon nanotubes are modified to make them water-soluble and functionalized as they can be linked to a variety of active molecules such as peptides, proteins, nucleic acids, and therapeutic agents [120, 121]. Nanotubes can be single walled or multiwalled [102]. Suitable polymers for nanoparticle preparation include poly (alkyl cyanoacrylates), poly(methylidenemalonate), and polyesters such as poly(lactic acid), poly(glycolic acid), poly(e-caprolactone), and their copolymers. poly( $\varepsilon$-caprolactone), poly(lactic acid) (PLA), poly(glycolic acid) (PGA), and their copolymers are most extensively researched due to their biocompatibility and biodegradability $[83,101]$. Table 1 illustrates some polymer based formulations that brought out positive results in recent research.

\section{Conclusion}

Nanotechnology has already revolutionized cancer therapy in many aspects and is radically changing the treatment pattern. It has made a great impact on selective recognizing of the cancerous cells, targeted drug delivery, and overcoming limitations of the conventional chemotherapies. Some nanotechnology based formulations have already been launched in the market and many are undergoing research and clinical trials. The side effects of the traditional chemotherapies can greatly be removed by these novel active or passive targeting which can substantially increase the survival rate. As cancer is one of the most serious lethal diseases, the contribution of nanotechnology in precise treatment avoiding the life threatening side effects can potentially contribute to a positive movement in clinical practice for life saving approach.

\section{Conflict of Interests}

The authors declare that there is no conflict of interests regarding the publication of this paper.

\section{References}

[1] D. J. Bharali and S. A. Mousa, "Emerging nanomedicines for early cancer detection and improved treatment: current perspective and future promise," Pharmacology and Therapeutics, vol. 128, no. 2, pp. 324-335, 2010.

[2] G. Zhao and B. L. Rodriguez, "Molecular targeting of liposomal nanoparticlesto tumor microenvironment," International Journal of Nanomedicine, vol. 8, pp. 61-71, 2013.

[3] N. R. Jabir, S. Tabrez, G. M. Ashraf, S. Shakil, G. A. Damanhouri, and M. A. Kamal, "Nanotechnology-based approaches in anticancer research," International Journal of Nanomedicine, vol. 7, pp. 4391-4408, 2012.

[4] S. A. Mousa and D. J. Bharali, "Nanotechnology-based detection and targeted therapy in cancer: nano-bio paradigms and applications," Cancers, vol. 3, no. 3, pp. 2888-2903, 2011.

[5] D. Peer, J. M. Karp, S. Hong, O. C. Farokhzad, R. Margalit, and R. Langer, "Nanocarriers as an emerging platform for cancer 
therapy," Nature Nanotechnology, vol. 2, no. 12, pp. 751-760, 2007.

[6] Y. Malam, M. Loizidou, and A. M. Seifalian, "Liposomes and nanoparticles: nanosized vehicles for drug delivery in cancer," Trends in Pharmacological Sciences, vol. 30, no. 11, pp. 592-599, 2009.

[7] K. B. Sutradhar and M. L. Amin, "Nanoemulsions: increasing possibilities in drug delivery," European Journal of Nanomedicine, vol. 5, no. 2, pp. 97-110, 2013.

[8] N. P. Praetorius and T. K. Mandal, "Engineered nanoparticles in cancer therapy," Recent Patents on Drug Delivery \& Formulation, vol. 1, no. 1, pp. 37-51, 2007.

[9] K. Park, "Nanotechnology: what it can do for drug delivery," Journal of Controlled Release, vol. 120, no. 1-2, pp. 1-3, 2007.

[10] L. A. Nagahara, J. S. H. Lee, L. K. Molnar et al., "Strategic workshops on cancer nanotechnology," Cancer Research, vol. 70, no. 11, pp. 4265-4268, 2010.

[11] K. T. Nguyen, "Targeted nanoparticles for cancer therapy: promises and challenges," Journal of Nanomedicine \& Nanotechnology, vol. 2, no. 5, article 103e, 2011.

[12] A. Coates, S. Abraham, and S. B. Kaye, "On the receiving endpatient perception of the side-effects of cancer chemotherapy," European Journal of Cancer and Clinical Oncology, vol. 19, no. 2, pp. 203-208, 1983.

[13] I. F. Tannock, C. M. Lee, J. K. Tunggal, D. S. M. Cowan, and M. J. Egorin, "Limited penetration of anticancer drugs through tumor tissue: a potential cause of resistance of solid tumors to chemotherapy," Clinical Cancer Research, vol. 8, no. 3, pp. 878884, 2002.

[14] R. Krishna and L. D. Mayer, "Multidrug resistance (MDR) in cancerMechanisms, reversal using modulators of MDR and the role of MDR modulators in influencing the pharmacokinetics of anticancer drugs," European Journal of Pharmaceutical Sciences, vol. 11, no. 4, pp. 265-283, 2000.

[15] M. Links and R. Brown, "Clinical relevance of the molecular mechanisms of resistance to anti-cancer drugs," Expert Reviews in Molecular Medicine, vol. 1999, pp. 1-21, 1999.

[16] M. M. Gottesman, C. A. Hrycyna, P. V. Schoenlein, U. A. Germann, and I. Pastan, "Genetic analysis of the multidrug transporter," Annual Review of Genetics, vol. 29, pp. 607-649, 1995.

[17] M. E. Davis, Z. Chen, and D. M. Shin, "Nanoparticle therapeutics: an emerging treatment modality for cancer," Nature Reviews Drug Discovery, vol. 7, no. 9, pp. 771-782, 2008.

[18] X. Guo and F. C. Szoka Jr., "Chemical approaches to triggerable lipid vesicles for drug and gene delivery," Accounts of Chemical Research, vol. 36, no. 5, pp. 335-341, 2003.

[19] S. Nie, Y. Xing, G. J. Kim, and J. W. Simons, "Nanotechnology applications in cancer," Annual Review of Biomedical Engineering, vol. 9, pp. 257-288, 2007.

[20] K. Cho, X. Wang, S. Nie, Z. Chen, and D. M. Shin, "Therapeutic nanoparticles for drug delivery in cancer," Clinical Cancer Research, vol. 14, no. 5, pp. 1310-1316, 2008.

[21] M. V. Yezhelyev, X. Gao, Y. Xing, A. Al-Hajj, S. Nie, and R. M. O’Regan, "Emerging use of nanoparticles in diagnosis and treatment of breast cancer," Lancet Oncology, vol. 7, no. 8, pp. 657-667, 2006.

[22] R. Duncan, "Polymer conjugates as anticancer nanomedicines," Nature Reviews Cancer, vol. 6, no. 9, pp. 688-701, 2006.

[23] M. Ferrari, "Cancer nanotechnology: opportunities and challenges," Nature Reviews Cancer, vol. 5, no. 3, pp. 161-171, 2005.
[24] D. A. LaVan, T. McGuire, and R. Langer, "Small-scale systems for in vivo drug delivery," Nature Biotechnology, vol. 21, no. 10, pp. 1184-1191, 2003.

[25] I. Brigger, C. Dubernet, and P. Couvreur, "Nanoparticles in cancer therapy and diagnosis," Advanced Drug Delivery Reviews, vol. 54, no. 5, pp. 631-651, 2002.

[26] S. I. Jeon, J. H. Lee, J. D. Andrade, and P. G. De Gennes, "Proteinsurface interactions in the presence of polyethylene oxide. I. Simplified theory," Journal of Colloid and Interface Science, vol. 142, no. 1, pp. 149-158, 1991.

[27] P. Tallury, S. Kar, S. Bamrungsap, Y.-F. Huang, W. Tan, and S. Santra, "Ultra-small water-dispersible fluorescent chitosan nanoparticles: synthesis, characterization and specific targeting," Chemical Communications, vol. 17, pp. 2347-2349, 2009.

[28] M. F. Francis, M. Cristea, and F. M. Winnik, "Polymeric micelles for oral drug delivery: why and how," Pure and Applied Chemistry, vol. 76, no. 7-8, pp. 1321-1335, 2004.

[29] G. Storm, S. O. Belliot, T. Daemen, and D. D. Lasic, "Surface modification of nanoparticles to oppose uptake by the mononuclear phagocyte system," Advanced Drug Delivery Reviews, vol. 17, no. 1, pp. 31-48, 1995.

[30] V. P. Torchilin and V. S. Trubetskoy, "Which polymers can make nanoparticulate drug carriers long-circulating?" Advanced Drug Delivery Reviews, vol. 16, no. 2-3, pp. 141-155, 1995.

[31] G. A. Mansoori, P. Mohazzabi, P. McCormack, and S. Jabbari, "Nanotechnology in cancer prevention, detection and treatment: bright future lies ahead," World Review of Science, Technology and Sustainable Development, vol. 4, no. 2-3, pp. 226-257, 2007.

[32] J. Sudimack and R. J. Lee, "Targeted drug delivery via the folate receptor," Advanced Drug Delivery Reviews, vol. 41, no. 2, pp. 147-162, 2000.

[33] J. F. Kukowska-Latallo, K. A. Candido, Z. Cao et al., "Nanoparticle targeting of anticancer drug improves therapeutic response in animal model of human epithelial cancer," Cancer Research, vol. 65, no. 12, pp. 5317-5324, 2005.

[34] G. Russell-Jones, K. McTavish, J. McEwan, and B. Thurmond, "Increasing the tumoricidal activity of daunomycin-pHPMA conjugates using vitamin B12 as a targeting agent," Journal of Cancer Research Updates, vol. 1, no. 2, pp. 1-6, 2012.

[35] G. L. Zwicke, G. A. Mansoori, and C. J. Jeffery, "Utilizing the folate receptor for active targeting of cancer nanotherapeutics," Nano Reviews, vol. 3, Article ID 18496, 3 pages, 2012.

[36] H. S. Yoo and T. G. Park, "Folate-receptor-targeted delivery of doxorubicin nano-aggregates stabilized by doxorubicin-PEGfolate conjugate," Journal of Controlled Release, vol. 100, no. 2, pp. 247-256, 2004.

[37] M. Kawamoto, T. Horibe, M. Kohno, and K. Kawakami, "A novel transferrin receptor-targeted hybrid peptide disintegrates cancer cell membrane to induce rapid killing of cancer cells," BMC Cancer, vol. 11, article 359, 2011.

[38] T. R. Daniels, B. Bernabeu, J. A. Rodríguez et al., "Transferrin receptors and the targeted delivery of therapeutic agents against cancer," Biochimica et Biophysica Acta, vol. 1820, no. 3, pp. 291317, 2012.

[39] N. C. Bellocq, S. H. Pun, G. S. Jensen, and M. E. Davis, "Transferrin-containing, cyclodextrin polymer-based particles for tumor-targeted gene delivery," Bioconjugate Chemistry, vol. 14, no. 6, pp. 1122-1132, 2003.

[40] C. R. Dass and P. F. M. Choong, "Targeting of small molecule anticancer drugs to the tumour and its vasculature using 
cationic liposomes: lessons from gene therapy," Cancer Cell International, vol. 6, article 17, 2006.

[41] H. K. Sun, H. J. Ji, H. L. Soo, W. K. Sung, and G. P. Tae, "LHRH receptor-mediated delivery of siRNA using polyelectrolyte complex micelles self-assembled from siRNA-PEGLHRH conjugate and PEI," Bioconjugate Chemistry, vol. 19, no. 11, pp. 2156-2162, 2008.

[42] S. S. Dharap, Y. Wang, P. Chandna et al., "Tumor-specific targeting of an anticancer drug delivery system by LHRH peptide," Proceedings of the National Academy of Sciences of the United States of America, vol. 102, no. 36, pp. 12962-12967, 2005.

[43] http://web.mit.edu/newsoffice/2006/prostate.html.

[44] T. M. Allen, "Ligand-targeted therapeutics in anticancer therapy," Nature Reviews Cancer, vol. 2, no. 10, pp. 750-763, 2002.

[45] P. Carter, "Improving the efficacy of antibody-based cancer therapies," Nature Reviews Cancer, vol. 1, no. 2, pp. 118-129, 2001.

[46] W. H. Ouwehand, R. Finnern, B. D. Gorick et al., "Selection of internalizing antibodies for drug delivery," Methods in Molecular Biology, vol. 248, pp. 201-208, 2004.

[47] J. D. Marks, W. H. Ouwehand, J. M. Bye et al., "Human antibody fragments specific for human blood group antigens from a phage display library," Bio/Technology, vol. 11, no. 10, pp. 11451149, 1993.

[48] B. Liu, F. Conrad, M. R. Cooperberg, D. B. Kirpotin, and J. D. Marks, "Mapping tumor epitope space by direct selection of single-chain Fv antibody libraries on prostate cancer cells," Cancer Research, vol. 64, no. 2, pp. 704-710, 2004.

[49] D. Peer, P. Zhu, C. V. Carman, J. Lieberman, and M. Shimaoka, "Selective gene silencing in activated leukocytes by targeting siRNAs to the integrin lymphocyte function-associated antigen-1," Proceedings of the National Academy of Sciences of the United States of America, vol. 104, no. 10, pp. 4095-4100, 2007.

[50] H. Wartlick, K. Michaelis, S. Balthasar, K. Strebhardt, J. Kreuter, and K. Langer, "Highly specific HER2-mediated cellular uptake of antibody-modified nanoparticles in tumour cells," Journal of Drug Targeting, vol. 12, no. 7, pp. 461-471, 2004.

[51] S. Sudarshan, D. H. Holman, M. L. Hyer, C. Voelkel-Johnson, J.-Y. Dong, and J. S. Norris, "In vitro efficacy of Fas ligand gene therapy for the treatment of bladder cancer," Cancer Gene Therapy, vol. 12, no. 1, pp. 12-18, 2005.

[52] O. Micheau, E. Solary, A. Hammann, F. Martin, and M.-T. Dimanche-Boitrel, "Sensitization of cancer cells treated with cytotoxic drugs to fas-mediated cytotoxicity," Journal of the National Cancer Institute, vol. 89, no. 11, pp. 783-789, 1997.

[53] G. N. Naumov, L. A. Akslen, and J. Folkman, "Role of angiogenesis in human tumor dormancy: animal models of the angiogenic switch," Cell Cycle, vol. 5, no. 16, pp. 1779-1787, 2006.

[54] M. A. J. Chaplain, "Mathematical modelling of angiogenesis," Journal of Neuro-Oncology, vol. 50, no. 1-2, pp. 37-51, 2000.

[55] J. Folkman, "Incipient angiogenesis," Journal of the National Cancer Institute, vol. 92, no. 2, pp. 94-95, 2000.

[56] N. Weidner, J. Folkman, F. Pozza et al., "Tumor angiogenesis: a new significant and independent prognostic indicator in earlystage breast carcinoma," Journal of the National Cancer Institute, vol. 84 , no. 24 , pp. $1875-1887,1992$.

[57] D. Fukumura and R. K. Jain, "Imaging angiogenesis and the microenvironment," APMIS, vol. 116, no. 7-8, pp. 695-715, 2008.

[58] M. Dhanabal, M. Jeffers, and W. J. LaRochelle, "Anti-angiogenic therapy as a cancer treatment paradigm," Current Medicinal Chemistry, vol. 5, no. 2, pp. 115-130, 2005.
[59] N. Weidner, J. P. Semple, W. R. Welch, and J. Folkman, “Tumor angiogenesis and metastasis-correlation in invasive breast carcinoma," The New England Journal of Medicine, vol. 324, no. 1, pp. 1-8, 1991.

[60] J. Folkman, "Fundamental concepts of the angiogenic process," Current Molecular Medicine, vol. 3, no. 7, pp. 643-651, 2003.

[61] D. Banerjee, R. Harfouche, and S. Sengupta, "Nanotechnologymediated targeting of tumor angiogenesis," Vascular Cell, vol. 3, article 3, 2011.

[62] N. Boudreau and C. Myers, "Breast cancer-induced angiogenesis: multiple mechanisms and the role of the microenvironment," Breast Cancer Research, vol. 5, no. 3, pp. 140-146, 2003.

[63] N. N. Khodarev, J. Yu, E. Labay et al., “Tumour-endothelium interactions in co-culture: coordinated changes of gene expression profiles and phenotypic properties of endothelial cells," Journal of Cell Science, vol. 116, no. 6, pp. 1013-1022, 2003.

[64] J. S. Desgrosellier and D. A. Cheresh, "Integrins in cancer: biological implications and therapeutic opportunities," Nature Reviews Cancer, vol. 10, no. 1, pp. 9-22, 2010.

[65] Y. Pan, H. Ding, L. Qin, X. Zhao, J. Cai, and B. Du, "Gold nanoparticles induce nanostructural reorganization of VEGFR2 to repress angiogenesis," Journal of Biomedical Nanotechnology, vol. 9, no. 10, pp. 1746-1756, 2013.

[66] S. A. Anderson, R. K. Rader, W. F. Westlin et al., "Magnetic resonance contrast enhancement of neovasculature with alpha(v)beta(3)-targeted nanoparticles," Magnetic Resonance in Medicine, vol. 44, pp. 433-439, 2000.

[67] J. H. Park, S. Kwon, J.-O. Nam et al., "Self-assembled nanoparticles based on glycol chitosan bearing $5 \beta$-cholanic acid for RGD peptide delivery," Journal of Controlled Release, vol. 95, no. 3, pp. 579-588, 2004.

[68] E. A. Waters, J. Chen, X. Yang et al., "Detection of targeted perfluorocarbon nanoparticle binding using $19 \mathrm{~F}$ diffusion weighted MR spectroscopy," Magnetic Resonance in Medicine, vol. 60, no. 5, pp. 1232-1236, 2008.

[69] P. M. Winter, A. M. Morawski, S. D. Caruthers et al., "Molecular imaging of angiogenesis in early-stage atherosclerosis with $\alpha \mathrm{v} \beta 3$-integrin-targeted nanoparticles," Circulation, vol. 108, no. 18, pp. 2270-2274, 2003.

[70] J. Li, J. Ji, L. M. Holmes et al., "Fusion protein from RGD peptide and $\mathrm{Fc}$ fragment of mouse immunoglobulin $\mathrm{G}$ inhibits angiogenesis in tumor," Cancer Gene Therapy, vol. 11, no. 5, pp. 363-370, 2004.

[71] E. Ruoslahti, "Cell adhesion and tumor metastasis," Princess Takamatsu Symposia, vol. 24, pp. 99-105, 1994.

[72] N. Ferrara, "VEGF as a therapeutic target in cancer," Oncology, vol. 69, no. 3, pp. 11-16, 2005.

[73] D. F. Baban and L. W. Seymour, "Control of tumour vascular permeability," Advanced Drug Delivery Reviews, vol. 34, no. 1, pp. 109-119, 1998.

[74] S. K. Hobbs, W. L. Monsky, F. Yuan et al., "Regulation of transport pathways in tumor vessels: role of tumor type and microenvironment," Proceedings of the National Academy of Sciences of the United States of America, vol. 95, no. 8, pp. 46074612, 1998.

[75] P. Rubin and G. Casarett, "Microcirculation of tumors Part I: anatomy, function, and necrosis," Clinical Radiology, vol. 17, no. 3, pp. 220-229, 1966.

[76] P. Shubik, "Vascularization of tumors: a review," Journal of Cancer Research and Clinical Oncology, vol. 103, no. 3, pp. 211226, 1982. 
[77] R. K. Jain and T. Stylianopoulos, "Delivering nanomedicine to solid tumors," Nature Reviews Clinical Oncology, vol. 7, no. 11, pp. 653-664, 2010.

[78] S. H. Jang, M. G. Wientjes, D. Lu, and J. L.-S. Au, "Drug delivery and transport to solid tumors," Pharmaceutical Research, vol. 20, no. 9, pp. 1337-1350, 2003.

[79] H. Maeda, "The enhanced permeability and retention (EPR) effect in tumor vasculature: the key role of tumor-selective macromolecular drug targeting," Advances in Enzyme Regulation, vol. 41, pp. 189-207, 2001.

[80] H. Maeda, J. Wu, T. Sawa, Y. Matsumura, and K. Hori, “Tumor vascular permeability and the EPR effect in macromolecular therapeutics: a review," Journal of Controlled Release, vol. 65, no. 1-2, pp. 271-284, 2000.

[81] F. Yuan, "Transvascular drug delivery in solid tumors," Seminars in Radiation Oncology, vol. 8, no. 3, pp. 164-175, 1998.

[82] http://www.pharmainfo.net/reviews/nanotechnology-reviewrevolution-cancer-treatment.

[83] G. Barratt, "Colloidal drug carriers: achievements and perspectives," Cellular and Molecular Life Sciences, vol. 60, no. 1, pp. 2137, 2003.

[84] E. M. Gordon and F. L. Hall, "Nanotechnology blooms, at last," Oncology Reports, vol. 13, no. 6, pp. 1003-1007, 2005.

[85] http://web.mit.edu/newsoffice/2010/nanoparticlechemotherapy-1005.html.

[86] A. K. Patri, J. F. Kukowska-Latallo, and J. R. Baker Jr., “Targeted drug delivery with dendrimers: comparison of the release kinetics of covalently conjugated drug and non-covalent drug inclusion complex," Advanced Drug Delivery Reviews, vol. 57, no. 15, pp. 2203-2214, 2005.

[87] N. Desai, "Challenges in development of nanoparticle-based therapeutics," The AAPS Journal, vol. 14, no. 2, pp. 282-294, 2012.

[88] C. E. Soma, C. Dubernet, D. Bentolila, S. Benita, and P. Couvreur, "Reversion of multidrug resistance by co-encapsulation of doxorubicin and cyclosporin A in polyalkylcyanoacrylate nanoparticles," Biomaterials, vol. 21, no. 1, pp. 1-7, 2000.

[89] M. L. Amin, "P-glycoprotein inhibition for optimal drug delivery," Drug Target Insights, vol. 7, pp. 27-34, 2013.

[90] H. Matsuo, M. Wakasugi, H. Takanaga et al., "Possibility of the reversal of multidrug resistance and the avoidance of side effects by liposomes modified with MRK-16, a monoclonal antibody to P-glycoprotein," Journal of Controlled Release, vol. 77, no. 1-2, pp. 77-86, 2001.

[91] S. Danson, D. Ferry, V. Alakhov et al., "Phase I dose escalation and pharmacokinetic study of pluronic polymer-bound doxorubicin (SP1049C) in patients with advanced cancer," British Journal of Cancer, vol. 90, no. 11, pp. 2085-2091, 2004.

[92] E. V. Batrakova, T. Y. Dorodnych, E. Y. Klinskii et al., "Anthracycline antibiotics non-covalently incorporated into the block copolymer micelles: in vivo evaluation of anti-cancer activity," British Journal of Cancer, vol. 74, no. 10, pp. 1545-1552, 1996.

[93] D. Goren, A. T. Horowitz, D. Tzemach, M. Tarshish, S. Zalipsky, and A. Gabizon, "Nuclear delivery of doxorubicin via folatetargeted liposomes with bypass of multidrug-resistance efflux pump," Clinical Cancer Research, vol. 6, no. 5, pp. 1949-1957, 2000.

[94] J. Kos, N. Obermajer, B. Doljak, P. Kocbek, and J. Kristl, "Inactivation of harmful tumour-associated proteolysis by nanoparticulate system," International Journal of Pharmaceutics, vol. 381, no. 2, pp. 106-112, 2009.
[95] A. Cirstoiu-Hapca, F. Buchegger, L. Bossy, M. Kosinski, R. Gurny, and F. Delie, "Nanomedicines for active targeting: physico-chemical characterization of paclitaxel-loaded antiHER2 immunonanoparticles and in vitro functional studies on target cells," European Journal of Pharmaceutical Sciences, vol. 38, no. 3, pp. 230-237, 2009.

[96] Y. B. Patil, U. S. Toti, A. Khdair, L. Ma, and J. Panyam, "Singlestep surface functionalization of polymeric nanoparticles for targeted drug delivery," Biomaterials, vol. 30, no. 5, pp. 859-866, 2009.

[97] W. Yang, Y. Cheng, T. Xu, X. Wang, and L.-P. Wen, "Targeting cancer cells with biotin-dendrimer conjugates," European Journal of Medicinal Chemistry, vol. 44, no. 2, pp. 862-868, 2009.

[98] Y. Liu, K. Li, J. Pan, B. Liu, and S.-S. Feng, "Folic acid conjugated nanoparticles of mixed lipid monolayer shell and biodegradable polymer core for targeted delivery of Docetaxel," Biomaterials, vol. 31, no. 2, pp. 330-338, 2010.

[99] O. Taratula, O. B. Garbuzenko, P. Kirkpatrick et al., "Surfaceengineered targeted PPI dendrimer for efficient intracellular and intratumoral siRNA delivery," Journal of Controlled Release, vol. 140, no. 3, pp. 284-293, 2009.

[100] Y. Patil, T. Sadhukha, L. Ma, and J. Panyam, "Nanoparticlemediated simultaneous and targeted delivery of paclitaxel and tariquidar overcomes tumor drug resistance," Journal of Controlled Release, vol. 136, no. 1, pp. 21-29, 2009.

[101] E. Brewer, J. Coleman, and A. Lowman, "Emerging technologies of polymeric nanoparticles in cancer drug delivery," Journal of Nanomaterials, vol. 2011, Article ID 408675, 2011.

[102] C. C. Anajwala, G. K. Jani, and S. M. V. Swamy, "Current trends of nanotechnology for cancer therapy," International Journal of Pharmaceutical Sciences and Nanotechnology, vol. 3, pp. 1043$1056,2010$.

[103] B. Haley and E. Frenkel, "Nanoparticles for drug delivery in cancer treatment," Urologic Oncology, vol. 26, no. 1, pp. 57-64, 2008.

[104] D. Lasic, "Doxorubicin in sterically stabilized," Nature, vol. 380, no. 6574, pp. 561-562, 1996.

[105] Y. Matsumura, T. Hamaguchi, T. Ura et al., "Phase I clinical trial and pharmacokinetic evaluation of NK911, a micelleencapsulated doxorubicin," British Journal of Cancer, vol. 91, no. 10, pp. 1775-1781, 2004.

[106] J. Kreuter and T. Higuchi, "Improved delivery of methoxsalen," Journal of Pharmaceutical Sciences, vol. 68, no. 4, pp. 451-454, 1979.

[107] D. Papahadjopoulos, T. M. Allen, A. Gabizon et al., "Sterically stabilized liposomes: improvements in pharmacokinetics and antitumor therapeutic efficacy," Proceedings of the National Academy of Sciences of the United States of America, vol. 88, no. 24, pp. 11460-11464, 1991.

[108] D. Peer and R. Margalit, "Loading mitomycin C inside long circulating hyaluronan targeted nano-liposomes increases its antitumor activity in three mice tumor models," International Journal of Cancer, vol. 108, no. 5, pp. 780-789, 2004.

[109] R. E. Eliaz and F.C. Szoka Jr., "Liposome-encapsulated doxorubicin targeted to CD44: a strategy to kill CD44-overexpressing tumor cells," Cancer Research, vol. 61, no. 6, pp. 2592-2601, 2001.

[110] S. R. Grobmyera, G. Zhoua, L. G. Gutweina, N. Iwakumab, P. Sharmac, and S. N. Hochwalda, "Nanoparticle delivery for metastatic breast cancer," Nanomedicine: Nanotechnology, Biology, and Medicine, vol. 8, pp. S21-S30, 2012. 
[111] Y. Liu, H. Miyoshi, and M. Nakamura, "Nanomedicine for drug delivery and imaging: a promising avenue for cancer therapy and diagnosis using targeted functional nanoparticles," International Journal of Cancer, vol. 120, no. 12, pp. 2527-2537, 2007.

[112] Y. Fukumori and H. Ichikawa, "Nanoparticles for cancer therapy and diagnosis," Advanced Powder Technology, vol. 17, no. 1, pp. 1-28, 2006.

[113] M. B. Yatvin, W. Kreutz, B. A. Horwitz, and M. Shinitzky, "pHsensitive liposomes: possible clinical implications," Science, vol. 210, no. 4475, pp. 1253-1255, 1980.

[114] S. K. Huang, P. R. Stauffer, K. Hong et al., "Liposomes and hyperthermia in mice: increased tumor uptake and therapeutic efficacy of doxorubicin in sterically stabilized liposomes," Cancer Research, vol. 54, no. 8, pp. 2186-2191, 1994.

[115] E. S. Kawasaki and A. Player, "Nanotechnology, nanomedicine, and the development of new, effective therapies for cancer," Nanomedicine, vol. 1, no. 2, pp. 101-109, 2005.

[116] A. Z. Wang, R. Langer, and O. C. Farokhzad, "Nanoparticle delivery of cancer drugs," Annual Review of Medicine, vol. 63, pp. 185-198, 2012.

[117] G. A. Hughes, "Nanostructure-mediated drug delivery," Nanomedicine: Nanotechnology, Biology and Medicine, vol. 1, pp. 22-30, 2005.

[118] S. M. Moghimi, A. C. Hunter, and J. C. Murray, "Nanomedicine: current status and future prospects," The FASEB Journal, vol. 19, no. 3, pp. 311-330, 2005.

[119] C. Kojima, K. Kono, K. Maruyama, and T. Takagishi, "Synthesis of polyamidoamine dendrimers having poly(ethylene glycol) grafts and their ability to encapsulate anticancer drugs," Bioconjugate Chemistry, vol. 11, no. 6, pp. 910-917, 2000.

[120] Z. Liu, K. Chen, C. Davis et al., "Drug delivery with carbon nanotubes for in vivo cancer treatment," Cancer Research, vol. 68, no. 16, pp. 6652-6660, 2008.

[121] A. Bianco, K. Kostarelos, and M. Prato, "Applications of carbon nanotubes in drug delivery," Current Opinion in Chemical Biology, vol. 9, no. 6, pp. 674-679, 2005. 

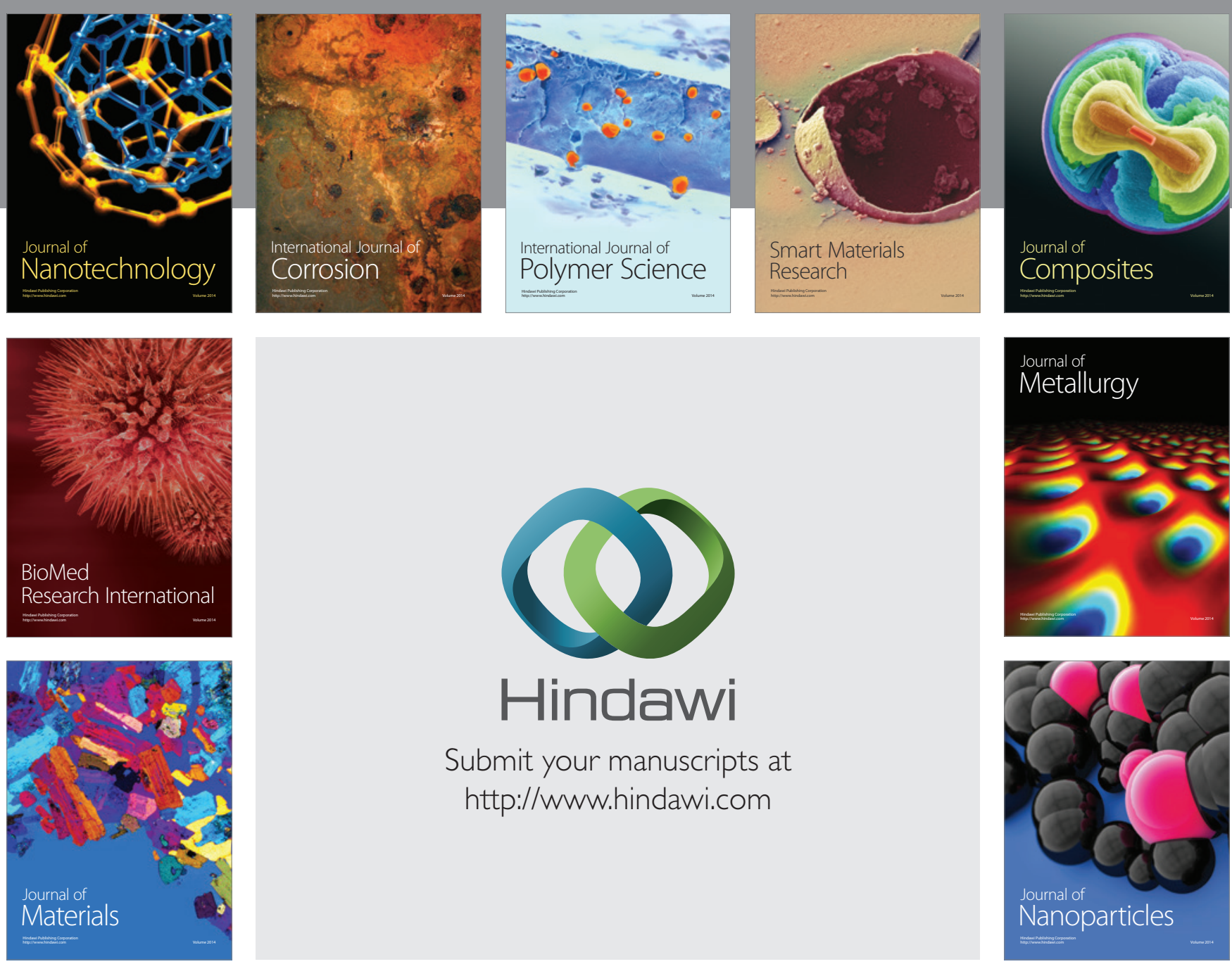

Submit your manuscripts at http://www.hindawi.com
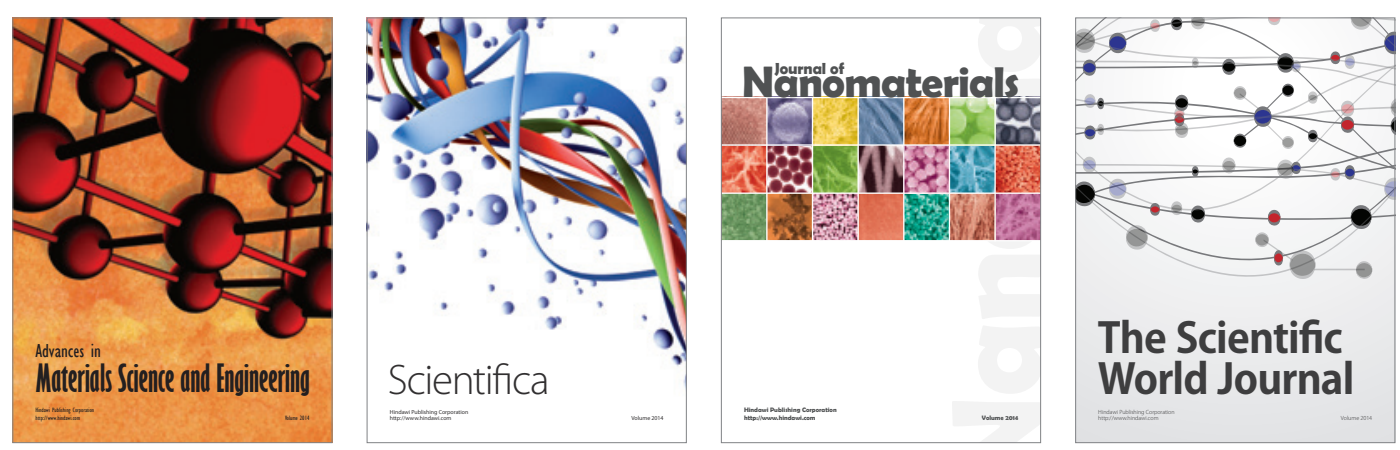

\section{The Scientific World Journal}
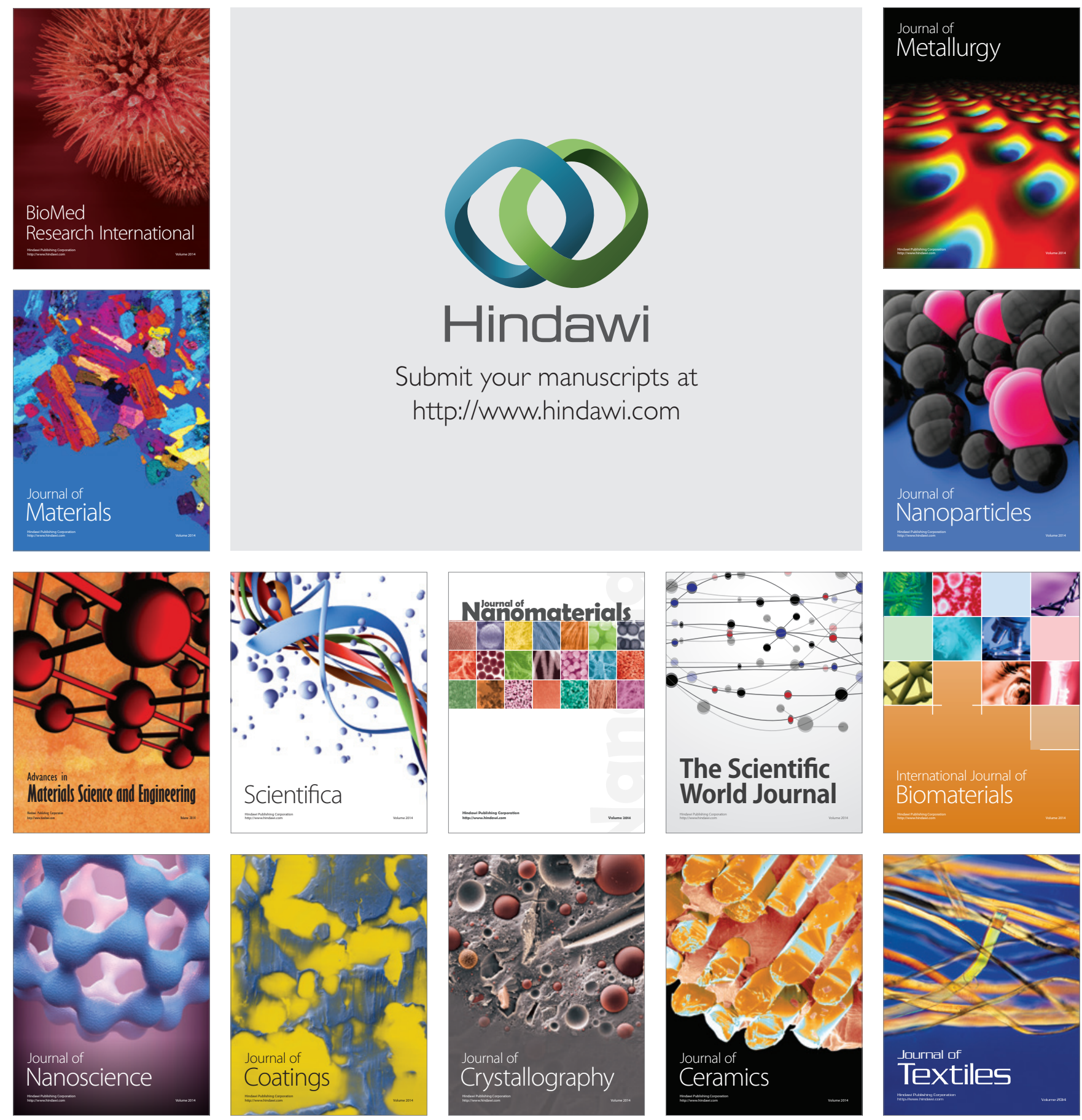